\title{
The Effect of Working Memory on EFL Learners' Oral Fluency
}

\author{
Mohammad Javad Rezai ${ }^{1} \&$ Bahareh Okhovat ${ }^{2}$ \\ ${ }^{1}$ Applied Linguistics, Yazd University, Yazd, Iran \\ ${ }^{2}$ TEFL, Yazd University, Yazd, Iran \\ Correspondence: Mohammad Javad Rezai, Yazd University, Yazd, Iran. E-mail: mrezai@yazd.ac.ir
}

Received: June 15, 2016 Accepted: July 3, 2016 Online Published: September 23, 2016

doi:10.5539/ijel.v6n5p74

URL: http://dx.doi.org/10.5539/ijel.v6n5p74

\begin{abstract}
Speaking is the primary objective of most L2 instructional programs and stands as one of the major factors in the evaluation of L2 learners' competence. The present study sought to investigate how preparation and task complexity can affect L2 learners' oral fluency in speech production with respect to individual differences in working memory capacity. The participants of the study consisted of 61 advanced L2 learners. The data collection consisted of two phases: a working memory test (reading span test) and a picture description task. Speaking was elicited through speech generation task in which the individuals were asked to discuss four topics emerging in two pairs. Also, each topic was accompanied by several relevant pictures. L2 fluency was assessed based on task complexity and preparation. The data were then analyzed in terms of the number of syllables, the number of silent pauses, and the mean length of pauses produced per minute. The statistical findings revealed that working memory, as a cognitive factor, played a significant role in L2 oral fluency accounting for variation in L2 performance. In addition, the variables Complexity and Preparation turned out to have a significant effect on the span groups' L2 oral performance. The study offers implications on strategies to improve learners' both fluency and working memory.
\end{abstract}

Keywords: working memory capacity, fluency, L2 speech production, task complexity

\section{Introduction}

A central issue in language learning is to find out what factors lead to variations in L2 performance among individuals. Recently, specifying what and how individual learner factors affect acquisitional processes among L2 learners is of much interest to linguists in second language acquisition (SLA) domain. In general, some variables have been found to contribute to variations among the learners including affective factors, cognitive factors and personality-related ones (Kormos \& Sáfár, 2008). Despite the fact that the role of working memory capacity has been found significant in L1 acquisition by some researchers. (e.g., Daneman, 1991; Daneman \& Green, 1986), it has not been much highlighted by L2 researchers as a cognitive factor. Hence, more attempts are required to investigate the impact of working memory on second language acquisition (Shahnazari, 2013).

In a broad sense, working memory is the human cognitive system responsible for the simultaneous and temporary processing and storage of information in the performance of cognitive activities such as comprehension, reasoning and learning (Baddeley, 2003).

As cited in Wen and Skehan (2011), the most commonly used model of working memory is the one developed by Baddeley and Hitch (1974), generally referring to the cognitive capacity to store and process information in real time. This cognitive construct is a multicomponent buffer consisting of three main parts: (a) central executive, responsible for information coordination, control and attention allocation, (b) phonological loop, responsible for handling phonological information, and (c) visuospatial sketchpad, being in charge of visual-spatial information.

Since working memory capacity is implicated in second language acquisition domain, one question arising here is whether this factor can contribute to variations in L2 performance among individuals. In the area of L2 acquisition and use, not enough studies have been carried out to investigate L2 fluency, as an L2 performance variable, from a cognitive perspective. In other words, there is little research investigating the role of individual differences in working memory and L2 performance (Mota, 2003). Alarge body of research has investigated how task characteristics may influence linguistic output (Mirdamadi \& De Jong, 2015), but not enough studies have focused on examining the effect of task complexity on L2 oral fluency with respect to individual differences in working memory. Also, investigating how planning and preparation affects second language production is an important 
issue which is important theoretically and practically to both second language acquisition (SLA) researchers and language practitioners (Ellis, 2005).

In the past few years, some empirical studies have been conducted suggesting the role of working memory in L2 skills development. Among others, Gu and Wang (2007) conducted an empirical study to investigate the role of executive working memory (EWM) in the listening process and its relationship with listening comprehension scores among Chinese EFL learners $(\mathrm{N}=59)$ at the university level. The results suggested that EWM was an effective predictor of the participants' listening comprehension performance. Moreover, studies conducted by Collentine, Freed, O'Brien, and Segalowitz (2006 \& 2007), indicated how the phonological loop of WM (or phonological memory as they called it) plays different roles for early and later L2 oral development. According to the researchers, the phonological working memory capacity plays a significant role in the development of L2 narrative skills at earlier stages of L2 learning (accounting for $17.5 \%$ of the variance), but the phonological working memory seems to play a more significant role in the correct use of function words when L2 learners reach a relatively high proficiency level (accounting for $15.7 \%$ of variance).

The findings of the above-mentioned studies point to the important role of working memory in L2 skills. However, such studies suffered from shortcomings including a small sample size, inappropriate statistical techniques, and lack of computer technology for a more accurate data analysis. In terms of investigating L2 fluency, the concepts were not clearly defined. More studies are required to have a better understanding of L2 speech performance from the perspective of individual differences in working memory capacity.

Regarding the impact of task characteristics on learners' L2 performance, Rahimpour (1997) conducted a study to investigate the impact of different types of cognitive tasks on learners' L2 performance. The results indicated that learners carrying out the most complex versions of the task were significantly less fluent, with no significant differences regarding either structural or lexical complexity. Also, considering the role of preparation in language production, the results of some empirical studies have indicated the positive effect of preparation on language production, especially written production in terms of complexity, accuracy, and fluency. For instance, some empirical studies have pointed to the positive effect of planning and preparation on the complexity and fluency of L2 learners' written production (Ahmadian, 2011; Yuan, 2001; Yuan \& Ellis, 2003). Although some empirical studies have proved the important effects of task complexity and preparation on language performance, still further studies are required to fully investigate the role of such factors with respect to individual differences in working memory. Moreover, in the EFL context it is not much clear to what extent these two factors (task complexity and preparation) can influence L2 learners' oral production, especially in terms of fluency. Hence, in line with such issues the current study was conducted to meet five purposes which are presented through the following research questions:

1) Can working memory differences affect L2 learners' oral fluency?

2) Is L2 oral fluency affected by the cognitive complexity of tasks?

3) Is L2 learners' fluency affected by the mode of presentation (prepared vs. Unprepared)?

4) Can working memory differences affect L2 learners' oral performance across task complexity and mode of presentation?

\section{Method}

\subsection{Participants}

The participants of the current study consisted of 61 MA students of TEFL studying at Yazd University as well as the instructors teaching English at Iran Language Institute in Yazd. They included both male and female individuals and all the participants' mother tongue was Persian. Moreover, the participants' age ranged between 22 and 40 (mean age: 26 ).

\subsection{Materials and Tasks}

The current study was carried out with the help of three types of data collection instruments including a general English proficiency test, a reading-span test and a speech generation task. The general English proficiency test was used to select the participants at or above advanced level for the study; the reading-span test was used to measure the participants' working memory capacity to place them in two groups (low/high-span group); and the speech generation task was used to elicit speech production in the L2.

\subsection{Procedure}

After selecting the participants through the Oxford Quick Placement Test, the participants underwent two experiments: the reading-span test and the speech generation task. For the reading-span test, developed by 
Shahnazari (2013), the participants were asked to judge each individual sentence grammatically aloud as they read them silently while their answer was recorded. They were also asked to recall the final word of each sentence in a set in the order in which they appeared. The whole test included three sets of 3,4,5, and 6 sentences for which the recall time increased based on the number of sentences.

To elicit speech in the speech generation task, the participants were required to discuss four topics including two simple topics and two cognitively demanding ones. The topics came in two pairs, each having one simple and one complex topic. The first pair came with planning time, letting the individuals get ready before speaking while the second pair had no planning time. Each topic was accompanied by several pictures related to the target topic so that the individuals could better express their ideas. In order to measure fluency, three temporal variables were used including the number of syllables, the number of silent pauses, and the mean length of pauses produced per minute. To analyze the number of syllables and the number of pauses, two software packages including Syllable Counter Software, and PRAAT 5.3.53 were employed respectively.

\section{Results}

The results obtained from the Persian reading span test led to the placement of 30 participants in the low-span group and 31 participants in the high-span group based on the determined mean score of the individuals $(\mathrm{M}=$ 75). The descriptive results of mixed ANOVA indicated that in terms of syllable production, high-span individuals outperformed their low-span counterparts in the four tasks. In addition, the high-span group tended to perform more successfully in more demanding tasks, especially those given no planning time $(M=165)$. The reverse was true for the low-span group. In other words, the low-span individuals tended to perform better in the context accompanied by a simple task planning time $(M=132.40)$. Table 1 presents the descriptive results.

Table 1. Descriptive statistics for span groups in terms of syllable production

\begin{tabular}{lllll}
\hline & Working Memory Capacity & Mean & Std. Deviation & N \\
\hline Simple Planned Task & Low working Memory & $\mathbf{1 3 2 . 4 0}$ & 15.813 & 30 \\
& High Working Memory & 155.10 & 23.086 & 31 \\
& Total & 143.93 & 22.765 & 61 \\
Simple Unplanned Task & Low working Memory & 117.23 & 19.213 & 30 \\
& High Working Memory & 147.84 & 29.591 & 31 \\
& Total & 132.79 & 29.227 & 61 \\
Complex Planned Task & Low working Memory & 121.50 & 14.219 & 30 \\
& High Working Memory & 150.42 & 29.085 & 31 \\
& Total & 136.20 & 27.078 & 61 \\
Complex Unplanned Task & Low working Memory & 118.67 & 19.231 & 30 \\
& High Working Memory & $\mathbf{1 6 5 . 0 3}$ & 27.344 & 31 \\
& Total & 142.23 & 33.149 & 61 \\
\hline
\end{tabular}

In addition, the inferential results revealed that the main effect of the variable Task was not significant with the value of 0.997 as shown by Wilks Lambda and a significance level of 0.68 suggesting a non-significant effect. Hence, the variable Task by itself was not a determining factor in syllable production of the participants. However, the interaction effect of Task * Memory turned out to be statistically significant with the value of .868 as shown by Wilks' Lambda and a significance level of 0.004 , indicating a statistically significant interaction effect. The partial eta-squared value was 0.13 suggesting a moderate effect size. These statistics indicate that the two span groups performed differently from each other in terms of task complexity. Another important point is related to the main effect of the second variable Preparation having a non-significant effect, with the value of 0.964 as shown by Wilks' Lambda and a significance level of 0.14 indicating a statistically non-significant effect. Similar to the first variable, i.e. Task, Preparation per se did not have a significant effect on the first fluency measure (syllable production) of the participants. Finally, the interaction effect of Preparation * Memory was significant with the value of 0.826 as shown by Wilks' Lambda and a significance level of 0.001, suggesting a statistically significant interaction effect. Also, the partial-eta squared value was 0.17 indicating a large effect size. Hence, the two span groups reacted differently to the four contexts in terms of preparation. In other words, the high-span group tended to produce more syllables in unplanned contexts while the low-span group tended to 
perform better with a higher number of syllables in planned contexts. The inferential information is presented in Table 2 below.

Table 2. Multivariate tests of the syllable production for the span groups

\begin{tabular}{lcccccc}
\hline Effect & Value & F & Hypothesis df & Error df & Sig. & Partial Eta Squared \\
\hline $\begin{array}{l}\text { Task } \\
\text { Wilks' Lambda }\end{array}$ & $\mathbf{. 9 9 7}$ & $.172^{\mathrm{a}}$ & 1.000 & 59.000 & $\mathbf{. 6 8 0}$ & .003 \\
$\begin{array}{l}\text { Task * Memory } \\
\text { Wilks' Lambda }\end{array}$ & $\mathbf{. 8 6 8}$ & $8.957^{\mathrm{a}}$ & 1.000 & 59.000 & $\mathbf{. 0 0 4}$ & .132 \\
$\begin{array}{l}\text { Preparation } \\
\text { Wilks' Lambda }\end{array}$ & $\mathbf{. 6 6 4}$ & $2.186^{\mathrm{a}}$ & 1.000 & 59.000 & $\mathbf{. 1 4 5}$ & .036 \\
$\begin{array}{l}\text { Preparation * Memory } \\
\text { Wilks' Lambda }\end{array}$ & $\mathbf{. 8 2 6}$ & $12.403 \mathrm{a}$ & 1.000 & 59.000 & $\mathbf{. 0 0 1}$ & $\mathbf{. 1 7 4}$ \\
\hline
\end{tabular}

Regarding the second fluency measure, namely the number of pauses, the high-span individuals outperformed their low-span counterparts in the four contexts in general. In addition, the high-span group tended to have fewer silent pauses (pauses more than 0.5 seconds) in the contexts accompanied by more demanding tasks, especially those given no planning time $(\mathrm{M}=3.71)$. On the contrary, the low-span group tended to perform more successfully in the contexts accompanied by simple tasks, especially those having planning time $(\mathrm{M}=8.17)$. To present the descriptive results, Table 3 is provided below.

Table 3. Descriptive statistics for the span groups in terms of pause mean

\begin{tabular}{lllll}
\hline & Working Memory Capacity & Mean & Std. Deviation & $\mathrm{N}$ \\
\hline Pause number - Simple Planned & Low working Memory & $\mathbf{8 . 1 7}$ & 4.308 & 30 \\
& High Working Memory & 6.03 & 4.572 & 31 \\
& Total & 7.08 & 4.536 & 61 \\
\hline Pause number - Simple & Low working Memory & 9.83 & 4.609 & 30 \\
Unplanned Task & High Working Memory & 4.87 & 3.914 & 31 \\
& Total & 7.31 & 4.918 & 61 \\
\hline Pause number - Complex Planned & Low working Memory & 9.20 & 4.180 & 30 \\
Task & High Working Memory & 5.68 & 4.902 & 31 \\
& Total & 7.41 & 4.859 & 61 \\
\hline Pause number - Complex & Low working Memory & 10.43 & 4.423 & 30 \\
Unplanned Task & High Working Memory & $\mathbf{3 . 7 1}$ & 3.662 & 31 \\
& Total & 7.02 & 5.258 & 61 \\
\hline
\end{tabular}

Concerning the inferential results, the variable Task with the value of 1 and the significance level of 0.921 , similar to the first fluency measure (syllable number), indicated a non-significant main effect on the individuals' production of silent pauses. Hence, this variable by itself did not have a significant role in oral fluency of L2 learners. However, as indicated below, the statistical findings revealed a significant interaction effect between Task and Memory with the value of 0.893 as shown by Wilks' Lambda and a significant value of 0.01 suggesting a statistically significant interaction effect. Also, the partial eta-squared value was 0.107 indicating a moderate effect size. These statistics indicate that the two span groups performed differently from each other across the four contexts in terms of task complexity; that is, the high-span individuals outperformed their low-span counterparts in more cognitively demanding tasks. Looking at the variable Preparation, the statistical results indicated a non-significant main effect with the value of 0.999 and a significance level of 0.857 suggesting an insignificant main effect. Thus, similar to the first variable, i.e. Task, the variable Preparation per se did not play a significant role in the second fluency measure (pause mean) of L2 learners.

However, the interaction effect of Preparation * Memory turned out to be significant with the value of 0.721 as shown by Wilks' Lambda and a significance level of 0.000 indicating a statistically significant interaction effect. The partial-eta squared value was 0.27 indicating a large effect size. These statistics suggest that for the second 
fluency measure, the two span groups reacted differently to the four contexts in terms of preparation. In other words, given preparation the low-span group tended to produce fewer silent pauses while the high-span group tended to perform more successfully with fewer pauses in unplanned context. Table 4 is provided below to present the inferential information.

Table 4. Multivariate tests of the pause mean for the span groups

\begin{tabular}{lllllll}
\hline Effect & Value & F & Hypothesis df & Error df & Sig. & Partial Eta Squared \\
\hline $\begin{array}{l}\text { Task } \\
\text { Wilks' Lambda }\end{array}$ & $\mathbf{1 . 0 0 0}$ & $.010^{\mathrm{a}}$ & 1.000 & 59.000 & $\mathbf{. 9 2 1}$ & .000 \\
\hline $\begin{array}{l}\text { Task * Memory } \\
\text { Wilks' Lambda }\end{array}$ & $\mathbf{. 8 9 3}$ & $7.100^{\mathrm{a}}$ & 1.000 & 59.000 & $\mathbf{. 0 1 0}$ & .107 \\
\hline $\begin{array}{l}\text { Preparation } \\
\text { Wilks' Lambda }\end{array}$ & $\mathbf{. 9 9 9}$ & $.033 \mathrm{a}$ & 1.000 & 59.000 & $\mathbf{. 8 5 7}$ & .001 \\
\hline $\begin{array}{l}\text { Preparation * Memory } \\
\text { Wilks' Lambda }\end{array}$ & $\mathbf{. 7 2 1}$ & $22.830 \mathrm{a}$ & 1.000 & 59.000 & $\mathbf{. 0 0 0}$ & $\mathbf{. 2 7 9}$ \\
\hline
\end{tabular}

Finally, in terms of the last fluency measure, i.e., the mean length of pauses, the descriptive results indicated that the mean score of the span groups was totally different across the four contexts. In other words, the high-span individuals outperformed their low-span counterparts in the four contexts and they tended to perform more successfully with lower length of pauses in the contexts accompanied by more cognitively demanding tasks, especially those given no planning time $(\mathrm{M}=3.10)$ while the low-span group could perform more successfully in the contexts accompanied by simple tasks, especially those given planning time $(\mathrm{M}=7.83)$. In order to present the descriptive results, Table 5 is provided below.

Table 5. Descriptive statistics for span groups in terms of pause length

\begin{tabular}{lllll}
\hline & Working Memory Capacity & Mean & Std. Deviation & N \\
\hline Pause Length - Simple & Low working Memory & $\mathbf{7 . 8 3 8}$ & 4.2228 & 30 \\
Planned Task & High Working Memory & 5.470 & 4.6121 & 31 \\
& Total & 6.635 & 4.5475 & 61 \\
\hline Pause Length - Simple & Low working Memory & 8.815 & 4.9334 & 30 \\
Unplanned Task & High Working Memory & 4.373 & 3.9571 & 31 \\
& Total & 6.558 & 4.9607 & 61 \\
\hline Pause Length - Complex & Low working Memory & 8.839 & 4.8843 & 30 \\
Planned Task & High Working Memory & 5.130 & 5.6414 & 31 \\
& Total & 6.954 & 5.5623 & 61 \\
\hline Pause Length - Complex & Low working Memory & 9.949 & 5.0733 & 30 \\
Unplanned Task & High Working Memory & $\mathbf{3 . 1 0 9}$ & 3.4664 & 31 \\
& Total & 6.473 & 5.5081 & 61 \\
\hline
\end{tabular}

In terms of the third fluency measure ( pause length), the inferential results revealed a non-significant main effect for the variable Task, similar to the previous fluency measures, with the value of 0.997 and a significance level of 0.66 . The statistics suggest that this variable by itself did not significantly affect the individuals' mean length of pauses. However, a significant interaction effect was found between task and memory with the value of 0.866 as shown by Wilks' Lambda and a significance level of 0.004 , proving a statistically significant interaction effect. The partial-eta squared value was 0.13 suggesting a large effect size. Thus, there was a sharp contrast between the span groups' mean length of pauses. In other words, the high-span group tended to have lower length of pauses in the four contexts, especially in the complex unplanned one $(M=3.10)$ whereas the low-span group could perform better with lower length of pauses in the simple planned context $(M=7.83)$. In addition, as shown below, the main effect of the variable Preparation turned out to be insignificant with the value of 0.99 and a significance level of 0.45. Thus, similar to the variable Task, Preparation per se did not have a significant effect on the span groups' 
mean length of pauses. On the contrary, the interaction effect of preparation and memory was significant with the effect value of 0.801 and a significance level of 0.000 indicating a statistically significant interaction effect. The partial-eta squared value was 0.199, suggesting a large effect size. Based on these statistics, the span groups performed quite differently across the four contexts with respect to preparation. Simply put, the high-span individuals tended to have lower length of pauses in the unplanned contexts, especially in the complex unplanned context $(\mathrm{M}=3.10)$ while the low-span group tended to perform relatively better in planned contexts, particularly in simple planned context $(\mathrm{M}=7.83)$. Table 6 is provided to present the inferential information.

Table 6. Multivariate tests of the pause length for the span groups

\begin{tabular}{lllllll}
\hline Effect & Value & F & Hypothesis df & Error df & Sig. & Partial Eta Squared \\
\hline $\begin{array}{l}\text { Task } \\
\text { Wilks' Lambda }\end{array}$ & $\mathbf{. 9 9 7}$ & $.184^{\mathrm{a}}$ & 1.000 & 59.000 & $\mathbf{. 6 6 9}$ & .003 \\
\hline $\begin{array}{l}\text { Task * Memory } \\
\text { Wilks' Lambda }\end{array}$ & $\mathbf{. 8 6 6}$ & $9.130^{\mathrm{a}}$ & 1.000 & 59.000 & $\mathbf{. 0 0 4}$ & .134 \\
\hline $\begin{array}{l}\text { Preparation } \\
\text { Wilks' Lambda }\end{array}$ & $\mathbf{. 9 9 0}$ & $.576^{\mathrm{a}}$ & 1.000 & 59.000 & $\mathbf{. 4 5 1}$ & .010 \\
\hline $\begin{array}{l}\text { Preparation * Memory } \\
\text { Wilks' Lambda }\end{array}$ & $\mathbf{. 8 0 1}$ & $14.645^{\mathrm{a}}$ & 1.000 & 59.000 & $\mathbf{. 0 0 0}$ & $\mathbf{. 1 9 9}$ \\
\hline
\end{tabular}

\section{Discussion}

The current study was conducted to meet four purposes in all. The first one was to find out whether working memory can affect L2 oral fluency. In general, using a mixed ANOVA, the statistical findings indicated a distinction in the two span groups' L2 speech production in terms of fluency measures. In other words, the low-span participants performed less successfully in the targeted tasks compared to their high-span counterparts. Therefore, addressing the first research question dealing with whether or not working memory differences can affect L2 learners' fluency, it can be safely assumed that the memory difference, as a cognitive factor, plays a determining part in L2 oral fluency and that task complexity can influence L2 oral fluency with respect to working memory differences. These results are in line with the results of the study conducted by Xhafaj (2006) proving the significant role of L2 working memory capacity in Brazilian participants' L2 fluency (as measured by pause distribution and mean length of run). In other words, L2 WMC correlated positively with the two fluency measures.

With respect to the second research question, asking whether or not fluency is affected by cognitive complexity of tasks, it can be mentioned that the obtained results from the present study suggested that the individuals' oral fluency was not significantly affected by task complexity itself $(p>0.05)$. However, this factor interacted significantly with individual differences in working memory. In line with such results, the findings of the studies by Robinson (1995) and Rahimpour (1997) provide evidence for the current results. They investigated the impact of different types of cognitive tasks on learners' $L 2$ performance and the results indicated that individuals tended to be more dysfluent in more demanding tasks.

Regarding the third research question, asking whether or not L2 fluency is affected by the mode of presentation (prepared vs. unprepared), the statistical findings obtained from the current study suggested that the variable "Preparation" per se did not play a statistically significant role in L2 learners' fluency with respect to the three measures, namely syllable number, silent pauses number, and the mean length of pauses $(p>0.05)$. However, this factor played a significant role in the oral fluency with respect to working memory differences. In other words, the low-span group tended to perform more successfully in the contexts given planning time while the high-span individuals were able to perform more successfully in the contexts without any planning time and preparation; therefore, the interaction effect between the working memory and preparation turned out to be significant in terms of the three fluency measures $(p<0.05)$. These results are in line with the findings of the study by Barati, Ketabi, and Piri (2012), who indicated that pre-task planning impacted the fluency (i.e., syllables per minute) of the EFL learner's written production significantly; however, it did not have a significant effect on the complexity and accuracy of the written performance. In addition, the findings of the study by Rahimpour and Safarie (2011) also indicated that pre-task planning had a significant effect on fluency, but no effect on complexity and accuracy. Although such studies do not take into account the role of individual differences in working memory, they point to the important role of preparation in L2 performance. Thus, more attention should be paid to such a variable when assessing L2 oral performance. 
Regarding the fourth research question, asking whether working memory differences affect L2 oral fluency across task complexity, the current results indicated a significant interaction effect between task and memory $(p<0.05)$. In other words, the span groups performed quite differently from each other in terms of task complexity. The high-span group performed much better in more cognitively demanding tasks while the low-span group tended to perform more successfully in simple tasks in comparison with their performance in other demanding tasks. The results are in line with the study by Mota (2003) pointing to the fact that individual working memory differences influence L2 oral performance and also individuals with a larger working memory capacity, as measured by the speaking span test, are able to speak faster and longer (between pauses and hesitations), with fewer errors, and more complexly than their low-span counterparts while producing a picture description task and a narrative task.

Since the role of working memory has been found significant in L2 oral performance, more attempts should be made to improve this cognitively limited capacity. To this end, while preparing textbooks, curriculum and material designers should include those types of cognitive tasks and cognitive exercises demanding more processing and information storage. In addition, there should be an attempt to provide learners with opportunities so that they can work with less cognitively demanding tasks first and then move on to more cognitively demanding tasks. This allows L2 learners to get better prepared to use their mental lexical items and structures resulting in a more fluent performance. A further important point is related to the role of preparation which has been proved in improving L2 output. According to Skehan (1996), when learners have the opportunity for planning the linguistic and propositional content of a task, they can compensate for these processing limitations, and consequently the quality of their linguistic output is enhanced. Therefore, teachers or syllabus designers should try to include and design sequences of instructional activities and tasks that provide opportunities for the learners to benefit from different types of planning in task performance.

\section{References}

Ahmadian, M. J. (2011). The effects of guided careful online planning on complexity, accuracy and fluency in intermediate EFL learners' oral production: The case of English articles. Language Teaching Research, $16(1), 1-21$.

Baddeley, A. (2003). Working memory and language: An overview. Journal of Communication Disorders, 36(3), 189-208. http://dx.doi.org/10.1016/S0021-9924(03)00019-4

Baddeley, A. D., \& Hitch, G. J. (1974). Working memory. The Psychology of Learning and Motivation, 8, 47-89. http://dx.doi.org/10.1016/S0079-7421(08)60452-1

Daneman, M. (1991). Working memory as a predictor of verbal fluency. Journal of Psycholinguistic Research, 20(6), 445-464. http://dx.doi.org/10.1007/BF01067637

Daneman, M., \& Green, I. (1986). Individual differences in comprehending and producing words in context. Journal of Memory and Language, 25(1), 1-18. http://dx.doi.org/10.1016/0749-596X(86)90018-5

Ellis, R. (2005). Planning and task-based performance: theory and research. In R. Ellis (Ed.), Planning and Task Performance in a Second Language. Amsterdam: John Benjamins. http://dx.doi.org/10.1075/1llt.11

Gu, S., \& Wang, T. (2007). Study on the relationship between working memory and EFL listening comprehension. CELEA Journal, 30, 46-56.

Kormos, J., \& Sáfár, A. (2008). Phonological short term-memory, working memory and foreign language performance in intensive language learning. Bilingualism: Language and Cognition, 11(2), 261-271. http://dx.doi.org/10.1017/S1366728908003416

Mirdamadi, F. S., \& De Jong, N. H. (2015). The effect of syntactic complexity on fluency: Comparing actives and passives in L1 and L2 speech. Second Language Research, 31(1), 105-116. http://dx.doi.org/10.1177/0267658314554498

Mota, M. B. (2003). Working memory capacity and fluency, accuracy, complexity, and lexical density in L2 speech production. Fragmentos: Revista de Lingua e Literatura Estrangeiras, 24.

O'brien, I., Segalowitz, N., Collentine, J., \& Freed, B. (2006). Phonological memory and lexical, narrative, and grammatical skills in second language oral production by adult learners. Applied Psycholinguistics, 27(3), 377-402. http://dx.doi.org/10.1017/S0142716406060322

O’brien, I., Segalowitz, N., Freed, B., \& Collentine, J. (2007). Phonological memory predicts second Language oral fluency gains in adults. Studies in Second Language Acquisition, 29(4), 557-581. http://dx.doi.org/10.1017/S027226310707043X 
Piri, F., Barati, H., \& Ketabi, S. (2012). The Effects of Pre-task, On-line, and both Pre-task and On-line Planning on Fluency, Complexity, and Accuracy-The Case of Iranian EFL Learners' Written Production. English Language Teaching, 5(6), 158. http://dx.doi.org/10.5539/elt.v5n6p158

Rahimpour, M. (1997). Task complexity and variation in oral L2 narrative discourse (Unpublished doctoral dissertation). CLTR, University of Queensland, Australia.

Rahimpour, M., \& Safarie, M. (2011).The effects of on-line and pre-task planning on descriptive writing of Iranian EFL learners. International Journal of English Linguistics, 1(2), 274-277. http://dx.doi.org/10.5539/ijel.v1n2p274

Robinson, P. (1995). Task complexity and second language narrative discourse. Language Learning, 45(1), 99-140. http://dx.doi.org/10.1111/j.1467-1770.1995.tb00964.x

Shahnazari, M. (2013). The development of a Persian reading span test for the measure of L1 Persian EFL learners' working memory capacity. Applied Research on English Language, 2(2), 107-116.

Skehan, P. (1996). A framework for the implementation of task-based instruction. Applied linguistics, 17(1), 38-62. http://dx.doi.org/10.1093/applin/17.1.38

Wen, Z., \& Skehan, P. (2011). A new perspective on foreign language aptitude research: building and supporting a case for "working memory as language aptitude". Ilhado Desterro A Journal of English Language, Literatures in English and Cultural Studies, 60, 15-44. http://dx.doi.org/10.5007/2175-8026.2011n60p015

Xhafaj, D. C. P. (2006). Pause distribution and working memory capacity in L2 speech production Florianópolis: UFSC, 2006. Unpublished master's thesis.

Yuan, F. (2001). The effects of planning on language production in task-based language teaching (Unpublished Doctoral dissertation). Temple University.

Yuan, F., \& Ellis, R. (2003). The effects of pre-task and on-line planning on fluency, complexity and accuracy in L2 monologic oral production. Applied Linguistics, 24(1), 1-27. http://dx.doi.org/10.1093/applin/24.1.1

\section{Copyrights}

Copyright for this article is retained by the author(s), with first publication rights granted to the journal.

This is an open-access article distributed under the terms and conditions of the Creative Commons Attribution license (http://creativecommons.org/licenses/by/4.0/). 